\title{
RELACIÓN ENTRE LA COMPOSICIÓN SOCIAL DE LA COMUNA Y LA DE LAS ESCUELAS EN LA REGIÓN METROPOLITANA DE SANTIAGO
}

\author{
Iván Ortiz ${ }^{1}$
}

\begin{abstract}
RESUMEN
Este artículo estudia la inclusión social escolar. Se investiga hasta qué punto la composición social de las escuelas se relaciona con la del territorio donde vive la gente, en el entendido de que este aspecto condicionaría las oportunidades de mixtura social escolar. Datos obtenidos de fuentes diversas como la prueba Simce 2013 de $4^{\circ}$ básico y la Encuesta Casen 2013 se usaron para averiguar si características comunales tales como el tamaño poblacional, el ingreso monetario de los hogares, la heterogeneidad social, la pobreza y otras, predicen la composición social escolar de las comunas en la Región Metropolita de Santiago. Puesto que se pone el foco en la inclusión social de la escuela - en un contexto general de segmentación - se propone un indicador apropiado para visibilizarla. La quinta parte de los estudiantes de $4^{\circ}$ básico en 2013 asistió a clases con compañeros de diversas condiciones socioeconómicas, en escuelas que podrían denominarse inclusivas. Se usó un modelo de regresión logística para ajustar los datos, el cual predijo mejor a las escuelas segregadas que a las mixtas, no obstante, entregó valiosas pistas para entender cómo las variables territoriales pueden afectar a la mixtura escolar.
\end{abstract}

Palabras clave: democratización de la educación, integración escolar, segregación escolar.

\section{RELATION BETWEEN SCHOOLS' AND MUNICIPALITIES' SOCIAL COMPOSITION IN THE SANTIAGO METROPOLITAN REGION}

\section{ABSTRACT}

This article addresses the social inclusion of schools. It explores the extent to which the social composition of schools is associated with that of the municipality, based on the premise that this would determine opportunities for school social mix. Data obtained from different sources, namely the fourth-grade results from Simce 2013 and the 2013 Casen Survey, were used to find out if variables based on territory such as population size, household monetary income, social heterogeneity and poverty would predict social composition of schools in the Santiago Metropolitan Area. Since the focus is on the social inclusion of the school, within a general context of segmentation, an appropriate indicator is proposed to make it visible. On average, 20\% of fourth-grade students in 2013 attended schools that could be categorized as mixed, with peers from diverse socioeconomic backgrounds. A logistic regression model was used to adjust the data. While the model better predicted segregated schools than mixed ones, it provided valuable clues to understand how territorial variables can affect school mix.

Keywords: democratization of education, school integration, school segregation.

Investigador independiente, Santiago, Chile. Contacto: ivanortizc@gmail.com 


\section{Introducción}

En 2015 se promulgó en Chile la Ley No 20.845 de Inclusión escolar que regula la admisión de los estudiantes, elimina el financiamiento compartido y prohíbe el lucro en establecimientos educacionales que reciben aportes del Estado. La admisión en los nuevos términos está entrando en vigencia en forma gradual, por regiones, permitiendo a las familias postular a sus hijos a cualquier establecimiento subvencionado, sin pagar por ello y sin ser discriminados arbitrariamente por sus antecedentes económicos, sociales o escolares, ni rendir pruebas de selección².

Esta ley es una respuesta de la política educacional —con apoyo de gran parte de la sociedad—, a la segregación social del sistema escolar. La composición social de los establecimientos escolares del país se caracteriza por la concentración excesiva de estudiantes desaventajados en algunos casos y aventajados en otros. La segregación resultante ha sido ampliamente descrita y problematizada en la literatura, tanto a nivel nacional como internacional (Bellei, 2013; Organisation for Economic Co-operation and Development, OECD, 2010; 2013). Esta situación sería consecuencia de una combinación de factores de diverso orden, que incluye a las políticas educacionales en interacción con las preferencias y los hábitos de las familias, todo operando en determinados contextos socioculturales, económicos y territoriales.

Controlar la composición social interna de la matrícula es una de las tareas educacionales más importantes de los gobiernos centrales y locales. Gorard (2015) ha mostrado que en Inglaterra el agrupamiento de los estudiantes desaventajados ha declinado a través del tiempo y que las políticas educativas han influido directamente en la desegregación escolar gracias, en gran parte, a la escolarización comprehensiva. En Francia, la segregación escolar ha sido activamente combatida gracias a políticas que dejaron en manos de autoridades municipales o inspectores ministeriales la afectación de los alumnos a las escuelas públicas sobre la base del lugar de residencia (Hébrard, 2002). Pese a las inevitables dificultades, el resultado ha sido un

Para el cuarto año de postulación, desde la promulgación de la Ley en mayo de 2016, en todas las regiones del país se aplicará el nuevo procedimiento de admisión. 
control de la segregación en niveles muy cercanos a la media de la OECD, en ambos países (OECD, 2010).

Se espera que la ley de inclusión escolar revierta la segregación. Para ello, tanto los oferentes de servicios educativos como los usuarios tendrán que cambiar sus prácticas, asimilando las nuevas regulaciones de admisión; estos últimos, desarrollando preferencias y elecciones de escuela compatibles con la desegregación. Sin embargo, las familias no necesariamente responden según lo esperado por los formuladores de políticas, pues no eligen escuela para sus hijos desde un vacío social; su elección se enmarca, entre otros factores, en el contexto territorial en el que habitan y hacen sus proyectos de vida (Condliffe, Boyd \& Deluca, 2015). En este sentido, la elección de escuela y la composición social resultante de ese proceso estarían, en gran parte, relacionadas con elementos fuera del alcance de las políticas educativas.

Este artículo examina la composición social de las comunas de la Región Metropolitana de Santiago (RMS), a través de una serie de variables sociodemográficas como: el ingreso promedio comunal, la distribución del ingreso, el nivel de pobreza, el tamaño poblacional y otras. Por otro lado, se desarrolla un procedimiento de clasificación de las escuelas que, pese a la segregación existente, visibiliza a los establecimientos integrados por estudiantes de diferentes niveles socioeconómicos. Luego, ambos conjuntos de variables se ponen en relación, buscando un modelo territorial que pueda predecir la mixtura escolar. En los antecedentes conceptuales, se remarca que la composición social de la escuela — y de la ciudad— tiene que ver con procesos económicos y sociales profundos, relacionados con el modelo de crecimiento del país. Se discute acerca de los procesos y los sujetos portadores eventuales de cambio.

\section{Antecedentes conceptuales}

El paisaje citadino de la RMS ha cambiado en los últimos 30 años, en lo que respecta a la composición de su base económica, su estructura social y su organización territorial (de Mattos, Riffo, Yáñez y Salas, 2005; de Mattos, Fuentes y Link, 2014). El nuevo paisaje responde en gran medida a las transformaciones ocurridas en los mercados de trabajo, 
reestructurados por un conjunto de factores económicos, sociales y tecnológicos, en un contexto de crecimiento económico importante en el período. De Mattos et al. (2005) analizaron datos de estructura ocupacional proveniente de los Censos 1992 y 2002 y diversas otras evidencias para mostrar que, además de los desplazamientos internos de población de altos y de bajos ingresos desde la parte central de la RMS hacia comunas del borde, también ha ocurrido una suerte de medianización, como ellos la llaman, de la estructura social.

En efecto, en el período intercensal, los grupos ocupacionales medios habrían aumentado de $32,8 \%$ a $36,4 \%$, que se traduce en un contingente de 228.952 habitantes. Por otra parte, el estudio constata una mayor diversificación social en algunas comunas o distritos, originalmente más populares, donde se han localizado sectores medios e, incluso, medios altos. Por ejemplo, se observó expansión de grupos medios en el área central, en los alrededores de Plaza Brasil, del Parque Forestal y en Santiago Poniente en general, y hacia los ejes San Miguel-La Cisterna y Macul-La Florida.

Paralelamente, se constató una fuerte disminución de los grupos obreros en casi todos sus distritos, quienes pasaron de contar con un $27,8 \%$ a 20,8\%, con una variación absoluta de -40.678 habitantes. Al mismo tiempo, aumentó la presencia relativa de los trabajadores del comercio y servicios, de 11,2\% a 13,8\% (variación absoluta de más de 110.000 habitantes), los que reemplazan en parte a los grupos obreros, dispersándose por casi todo el mapa metropolitano.

La medianización observada en la RMS ocurre en forma paralela a otros procesos atribuidos al modelo de acumulación neoliberal. Los autores no encontraron en su estudio evidencias de polarización, pero sí de exacerbación de la desigualdad socioeconómica. Al respecto, es útil distinguir entre desigualdad y polarización. En el estudio se cita a Hamnnett (2003), quien aclara que desigualdad se refiere a la magnitud de la dispersión entre diferentes niveles de ingresos/ salarios: si los ricos son cada vez más ricos y/o los pobres son cada vez más pobres, lo que aumenta es la desigualdad, no necesariamente la polarización. Esta, se refiere a los cambios en el tamaño de diferentes grupos de ingresos/salarios a lo largo del tiempo. Cuando aumentan 
los ricos y/o los pobres, en detrimento de los grupos medios, se habla de polarización, fenómeno que los datos anteriores no avalarían.

Los datos anteriores no contradicen tampoco la segregación residencial que se observa en el paisaje urbano de la RMS. Esta ocurre cuando un grupo(s) social(es) se localiza(n) preferentemente en algunas zonas o comunas de la ciudad por sobre otras, y también cuando, al interior de ciertas comunas o zonas de la ciudad existe presencia de uno u otro grupo social en proporción superior al promedio (Link, Valenzuela y Fuentes, 2015). La segregación residencial socioeconómica sería una característica de muchas ciudades chilenas, como Santiago, Valparaíso y Concepción (Sabatini, Cáceres y Cerda, 2001); en cambio, la del resto del país, de unidades menores que las grandes ciudades, se ha estudiado poco o nada.

La segregación residencial y la escolar, según varios autores, se influyen recíprocamente (Frankenberg, 2013; Stillerman, 2016). Las zonas residenciales definen concretamente los barrios a los que se asocian las escuelas, lo que hace difícil separar las decisiones residenciales de las preferencias escolares; las familias con recursos económicos pueden comprar en barrios bien avaluados con escuelas supuestamente mejores, no así las familias pobres (SiegenHawley, 2013). En Chile, Valenzuela, Bellei y de los Ríos (2009) muestran que la segregación residencial predice la segregación escolar de los estudiantes pertenecientes al 30\% inferior de nivel socioeconómico, NSE, en una muestra de 51 comunas chilenas. Así, hogares pertenecientes a comunas segregadas pobres elegirían una escuela cercana, donde se encontrarían los mismos del vecindario. Considérese que la cercanía al domicilio es un criterio importante de elección de escuela, especialmente en poblaciones de escasos recursos, si otras condiciones se mantienen constantes (Córdoba, 2013; Hernández y Raczynski, 2015; Thieme y Rojas, 2009)33. Según lo anterior, la mixtura escolar se vería limitada por este hecho.

El hecho de que la gran mayoría de los estudiantes de educación básica asista a una escuela en la misma comuna donde su familia decidió habitar (Donoso y Arias, 2013) evidencia el peso del domicilio en la elección de escuela. Según estos autores el $11 \%$ en promedio asiste a una escuela en otra comuna, a nivel nacional. En el Gran Santiago, esa cifra es 22\%. En educación media en RM, salta al 50\%, la más alta del país; la autonomía de los jóvenes, la ruptura escuela-liceo, la contigüidad de las comunas, la búsqueda de calidad y otras razones, explican ese salto. 
No obstante, no sería este un fenómeno generalizado. En los barrios y sectores internos de las ciudades de menor tamaño habría un grado importante de diversidad social, o al menos habría posibilidades "de integración social urbana mayores que las que habitualmente anticipamos" (Sabatini y Brain, 2008, p. 2). Link et al. (2015) estudiaron la composición socioocupacional de la RMS aplicando un enfoque de tipologías socioespaciales, que les permitió revelar de mejor forma la complejidad de los grupos sociales existentes al interior de cada unidad (distritos censales, comunas). Es interesante notar en estudios como este y el de De Mattos et al. (2005), que prácticamente todas las comunas albergan residentes pertenecientes a los distintos grupos de la jerarquía ocupacional. En diferentes proporciones, por supuesto. Por ejemplo, que los grupos medios constituían el 45\% de la comuna de Independencia según el Censo de 2002, sorprende poco; menos conocido es que el 39\% de Vitacura era también de grupos medios. Pero mientras solo el 8\% de los habitantes de la primera comuna pertenecía a los grupos dirigentes, en la segunda era el 31\%. De Mattos et al. (2005) observan que en escalas reducidas (nivel de distrito o de manzana) es posible identificar formas específicas y sutiles tanto de segregación como de mezcla social. Evidencia reciente muestra, por ejemplo, que las distintas comunas contribuyen en forma muy diversa a la segregación residencial del Gran Santiago (Agostini, Hojman, Román y Valenzuela, 2016) ${ }^{4}$. Parece que, en parte, el indicador de segregación usado influye en los resultados; y han aparecido índices alternativos al tradicional D de Duncan que dan mejor cuenta del fenómeno (Martori y Apparicio, 2011; Martori, Hoberg y Surinach, 2006).

Según Sabatini y Brain (2008), el sector inmobiliario privado ha contribuido a modificar el patrón tradicional de segregación residencial de manera que, paradójicamente, ha conllevado a una reducción en la distancia física entre grupos sociales. Los patrones emergentes serían dos. Uno, el poblamiento de zonas próximas a la gran ciudad, de atractivo ecológico, a las que llegan a habitar familias de ingresos medios y altos (Ruiz Tagle y López, 2014); en

Tampoco se encuentran estudios de la segregación residencial con datos actuales en Chile, debido a que la medición de este fenómeno necesita datos censales de población, los cuales están limitados al último censo de 2002. 
ese espacio conviven con lugareños de escasos recursos y/o con pobladores de conjuntos de viviendas sociales que se han instalado en las inmediaciones. Dos, otra figura se origina en la construcción de proyectos grandes (torres, condominios) de viviendas en zonas relativamente alejadas de los barrios altos tradicionales, resultando en enclaves de alta homogeneidad social, pero cercanos en distancia física a las zonas de residencia de grupos más pobres. De esta manera, la segregación no desaparece, pero ocurre en una escala geográfica menor, cercana a la forma que tomaría la diversidad social residencial.

Nótese el parentesco de este patrón no tradicional de segregación con el concepto de gentrificación, utilizado en el estudio de las ciudades. Se entiende por este, un proceso en el que individuos o familias de ingreso más alto se mueven a comunas o barrios de ingresos más bajos que poseen cualidades atractivas, atraídos por el valor de las propiedades: bajo al inicio, este valor sube después como consecuencia del incremento de la demanda. La gentrificación se concibe como una fuerza poderosa que moldea las ciudades contemporáneas (Doucet, 2014). El concepto no está exento de controversia. Metodológicamente, se discuten los criterios cuantitativos y cualitativos (Barton, 1916) para atribuir la presencia del fenómeno. Algunos remarcan las consecuencias positivas de este proceso, como el reequipamiento y la revitalización del barrio o comuna; otros, las negativas, como el desplazamiento de los vecinos más pobres.

En la versión clásica, el concepto enfatiza el retorno de la clase alta o media alta, desde las áreas periféricas al centro de la ciudad, el protagonismo de profesionales en la treintena, sin hijos, la instalación de nuevos servicios afines a las necesidades y gustos de los recién llegados, la elitización del barrio, el desplazamiento de los residentes antiguos, el movimiento de capitales inmobiliarios. Actualmente, se informa de un uso más abierto que el clásico, que capta las nuevas facetas de revitalización urbana de ciudades de diversas latitudes, mediante el despliegue de individuos y familias de clases medias profesionales y técnicas más amplias, de estilos de vida diversos, con apoyo del sector público, nueva construcción en la periferia y 
en antiguos barrios industriales de la ciudad (Doucet, 2014; Hwang, 2016; Landis (2015) muestra que la llegada de vecinos con más poder económico puede acarrear molestias a los antiguos vecinos, pues los servicios se adaptan a los gustos de los nuevos residentes y suben los impuestos de las propiedades, pero no necesariamente su desplazamiento. No obstante, el significado original permanece: proceso de revitalización de barrios empobrecidos de bajos ingresos por la acción de nuevos grupos de mayor capital cultural y económico que se instalan allí aprovechando una brecha de renta favorable (López-Morales, Shin \& Lees, 2016).

Entendemos que la medianización aludida en el estudio por De Mattos et al. (2005) fue la base de sustentación de un proceso de gentrificación protagonizado por grupos de ingreso medio que, además de aumentar en número, cambiaron de lugar residencial. Las relaciones que este proceso tiene con la elección de escuela y con su composición social son plausibles y en otros países se observan con interés (Jordan y Gallagher, 2015), aunque no han sido aún sistematizadas en la literatura. En las escuelas del barrio donde llegan padres gentrificadores se encuentran con la comunidad local, generando oportunidades de integración, pero también dinámicas de marginación. Por ejemplo, se conciertan para elegir las mejores escuelas públicas del barrio donde llegan, saturando los cupos y desplazando a los antiguos residentes (Butler, Hamnett \& Ramsden, 2013).

Un factor que podría predecir la mixtura escolar es el nivel de desigualdad de ingresos de la población que habita una zona determinada. La heterogeneidad de ingresos en un espacio residencial relativamente acotado haría teóricamente posible la mezcla escolar. Es decir, es más probable que ocurra mixtura escolar allí que en las comunas de ingreso parejo, ya sea alto o bajo. Afortunadamente, los estudios de desigualdad social, a diferencia de los de segregación, sí han llegado a analizar el nivel comunal (Agostini y Brown, 2007; Modrego, Ramírez y Tartakowsky, 2009).

Algunos autores enfatizan las ventajas funcionales para los hogares pobres, tales como oportunidades de empleo y comercio. Otros señalan que la proximidad hace más evidente la confrontación 
y la violencia simbólica de las rejas divisorias. Ruiz Tagle (2016) no encontró evidencias de integración socioespacial entre vecinos de diferentes grupos socioeconómicos en su estudio de barrios mixtos de La Florida (Santiago); por el contrario, encontró una persistente estigmatización, desconfianza mutua y ventajas funcionales nimias para los más pobres. Rasse (2015) estudió cuatro casos de fronteras entre hogares de distinto nivel socioeconómico en cuatro comunas del Gran Santiago y halló que, en términos de inclusión social (es decir, acceso a oportunidades), en todos los casos la llegada de hogares de altos ingresos significó ventajas funcionales para los hogares de bajos ingresos. En términos de cohesión social (significados compartidos), sin embargo, la situación fue más compleja, con aspectos positivos y negativos en cada caso. Destaca que la mera observación del otro en sus rutinas es una fuente de cohesión social, en la medida en que permite cierta identificación con el otro, la que es perturbada principalmente por el temor a la delincuencia, la percepción de casos de mal vivir y la de que alguna gente alcanza un mejor estatus, no por esfuerzo, sino por herencia. Sabatini, Rasse, Mora y Brain (2012) también hallaron que la delincuencia y los conflictos son barreras que la gente teme frente a una eventual integración social residencial. Dicho sea de paso, las dinámicas de interacción que ocurren en espacios de integración social residencial podrían dar pistas interesantes de lo que podría ocurrir en escuelas socialmente diversas.

El tamaño poblacional de la localidad también afectaría las oportunidades de mixtura escolar. Los mercados de suelo y vivienda se activarían en mayor medida en lugares populosos, generando segregación; se sabe que la relación entre segregación residencial y estos mercados es estrecha (Sabatini y Brain, 2008). Por otra parte, los establecimientos privados de pago y copago alto no se instalan en localidades pequeñas donde no se logra acumular una cantidad suficiente de familias de ingresos altos.

La desigualdad socioeconómica, la segregación residencial, el nivel de ingreso comunal y otras características territoriales varían en forma independiente de las otras y se afectan mutuamente, haciendo inseguro cualquier pronóstico a partir de una sola. Por 
ejemplo, Cerro Navia con un índice de Duncan ${ }^{5}$ de 0,14 era tan poco segregada como la comuna de Santiago (que contaba con un índice Duncan 0,15 en 2002), pero con menos de la mitad de su ingreso per cápita promedio; por otro lado, era menos desigual que Santiago, con índices de Gini 0,39 y 0,47, respectivamente (Modrego et al., 2009).

Con estos antecedentes y conjeturas en mente, en las próximas páginas se explora empíricamente la relación entre la composición social escolar y algunas características sociodemográficas de las comunas de la RMS, como el ingreso promedio de las familias, la desigualdad socioeconómica, el nivel de pobreza, el tamaño poblacional, la superficie territorial, el nivel de delincuencia. No se cuenta con indicadores de segregación residencial actual de las comunas, ni de gentrificación, como hubiera sido deseable.

Fue necesario innovar en el método de análisis de la composición social del sistema escolar. Investigaciones chilenas han usado el Índice D como indicador de segregación escolar (Gallego \& Hernando, 2008; Ministerio de Educación de Chile, Mineduc, 2012; Valenzuela et al., 2009; Valenzuela, Bellei y de los Ríos, 2014) ${ }^{6}$. Otro índice considera toda la dispersión del nivel socioeconómico de los estudiantes, descomponiendo la variabilidad total en dos partes, la encontrada entre escuelas y la encontrada al interior de estas ${ }^{7}$. Ha sido usado por el Programme for International Student Assessment (PISA) para comparar la segregación escolar de más de cincuenta países. Ambos son índices sintéticos, en el sentido de que capturan en una cifra la situación de segregación que existe en un sistema determinado como un todo, al costo de invisibilizar la situación de

Índice de Disimilitud o D; es el más indicador más usado de segregación residencial. Mide la distribución de un determinado grupo de población en un espacio, varía entre 0 y 1.

6 Aplicado a la situación escolar, este índice representa el porcentaje de estudiantes desaventajados que deben ser transferidos entre establecimientos escolares para que exista una distribución homogénea de ellos entre todos los que pertenecen a un determinado territorio (Valenzuela et al., 2014).

7 El índice representa la proporción de la varianza total encontrada al interior de las escuelas: si es alta, significa que en su interior conviven estudiantes de una amplia diversidad de estatus socioeconómico (OECD, 2010). En los sistemas escolares segregados, como el de Chile, se caracterizan por una alta variabilidad del nivel socioeconómico entre las escuelas, y poca variabilidad al interior de estas. 
sus unidades constituyentes. Existe otro indicador de composición social —aplicable a cualquier nivel de agregación— más apropiado a los fines de este artículo, que se explicará a continuación.

\section{Método}

El método se divide en dos partes. En la primera se siguió un procedimiento para identificar y clasificar a los establecimientos educacionales del país según su composición social interna. En la segunda, se reunieron datos territoriales de las comunas de la Región Metropolitana y se puso en relación la clasificación anterior de las escuelas de esa región con las variables independientes, mediante análisis de regresión logística.

\subsection{Clasificación de las escuelas}

Se usó el indicador de composición social de Monseur y Crahany $(2008)^{8}$. Este se basa en la clasificación de las escuelas en tres grupos de acuerdo con su NSE, el cual se obtiene del NSE de los estudiantes. Si el promedio de la escuela es significativamente inferior al promedio nacional, entonces pertenece al grupo de las escuelas desaventajadas; si es superior, al de las aventajadas. El tercer grupo es el conformado por las escuelas del intervalo de confianza que no difiere significativamente del promedio nacional.

Se utilizaron las bases de datos del Sistema de Medición de la Calidad de la Educación (SIMCE), que en 2013 evaluó a todos los estudiantes de $4^{\circ}$ básico del país y encuestó a sus padres y a sus establecimientos. Para complementar algunos análisis, también se usaron las bases de datos de esa medición en $8^{\circ}$ básico. La construcción de la variable NSE del estudiante, entonces, fue derivada de las respuestas de los padres a las preguntas por la escolaridad de la madre y del padre (expresadas en número de años de escolaridad) y por el ingreso familiar (expresada en pesos, puntos medios de los intervalos de la escala de ingreso). Los valores perdidos en alguna de las tres variables — numerosos y no completamente al azar- fueron

Posteriormente, ha sido usado en los análisis de resultados de la evaluación internacional PISA (OECD, 2010; 2012; 2013). 
imputados con valores predichos basados en una regresión sobre las dos variables restantes.

Luego de la imputación de valores, las tres variables fueron sometidas a un análisis de componentes principales. En definitiva, los valores de la variable creada, NSE, fueron obtenidos como puntajes factoriales de la primera componente principal, con promedio $0 \mathrm{y}$ desviación estándar 1. La primera componente principal capturó el $73,6 \%$ de la varianza total de la escolaridad de la madre y del padre y el ingreso familiar, y correlacionó ,86; ,88; y ,83 con cada variable de origen, respectivamente.

Una vez obtenido el NSE del estudiante, se calculó el promedio nacional y el de cada escuela. Luego, se dividió a las escuelas en tres grupos de acuerdo con su NSE: bajo el promedio nacional; sobre el promedio nacional; y escuelas que no difieren significativamente del promedio nacional $(t=+-1,96)$. Adicionalmente, se determinó el quintil de NSE correspondiente a cada alumno y se analizaron las composiciones sociales internas de cada grupo. Las escuelas del tercer grupo pueden, en principio, estar compuestas por estudiantes de un NSE homogéneo en torno al promedio nacional, o bien por estudiantes de diferentes NSE cuyo promedio sea cercano al nacional. En este último caso, tales escuelas se consideran socialmente mixtas.

\subsection{Construcción de las variables territoriales}

Se construyó una base de datos económicos y demográficos de las comunas de la RMS con información de diferentes fuentes, entre ellas, la Encuesta de Caracterización Socioeconómica Nacional (CASEN) 20139. Es sabido que dicho instrumento no es representativo de (todas) las comunas, limitación que los encargados tratan de resolver para tomar decisiones confiables de ayuda social en ese nivel. Este estudio toma el riesgo de usar datos comunales de esa procedencia, debido a que ese año la Encuesta Casen utilizó la metodología de "small area estimates", para fortalecer la calidad de las estimaciones

9 El Gobierno de Chile, a través del Ministerio de Desarrollo Social, aplica esta encuesta periódicamente para determinar los niveles de pobreza y desigualdad social y económica en el país. 
realizadas sobre áreas o poblaciones pequeñas que no tienen representación estadística, como las comunas; combinó el cálculo directo desde la Encuesta Casen con una predicción realizada a partir de un modelo estadístico que consideró información procedente de otras fuentes administrativas y censales (Casas-Cordero, Krause y Herrera, 2011). Así, la información acerca de ingresos y de población, decisiva en estudios de pobreza, fue sometida a un análisis de validación con el objeto de detectar la presencia de posibles sesgos de medición. El diseño muestral y la elaboración de los factores de expansión fueron provistos por el Instituto Nacional de Estadísticas (INE). La descripción más detallada de las variables independientes del estudio es la siguiente:

- Población comunal. Corresponde al número de habitantes de la comuna, según estimaciones del último Censo Nacional de 2016-2017 del Instituto Nacional de Estadísticas (INE, 2017b). Se consideró más fidedigno este dato que la proyección para 2013 de la población a partir del Censo de 2002 (INE, 2017a).

- Superficie comunal. Área de la comuna, expresada en kilómetros cuadrados. Información extraída de la plataforma web de la Subsecretaría de Desarrollo Regional, específicamente del Sistema Nacional de Información Municipal. Números más altos revelan superficies extensas.

- Ingreso comunal. Corresponde al promedio comunal del ingreso per cápita total del hogar de la Encuesta Casen 2013, en pesos. Cifras altas indican mayor solvencia económica.

- Índice de homogeneidad social comunal. Casen informa el quintil de ingreso autónomo, regional y nacional, de cada encuestado. A partir de este dato, se determinó para cada comuna su composición social, en términos de la proporción de sus habitantes en los quintiles de la Región Metropolitana. Por ejemplo: comuna X tiene $2 \%$ de habitantes en el primer quintil regional, $18 \%$ en el segundo, $30 \%$ en el tercero, $30 \%$ en el cuarto, 20\% en el quinto; comuna Y tiene 30\%, 35\%, 25\%, 9\% y $1 \%$, respectivamente. El índice corresponde a la desviación estándar interquintiles resultante. Comunas cuya gente está repartida equitativamente en los cinco quintiles de ingreso, 
tienen una desviación estándar igual a 0, representando máxima heterogeneidad social, comparativamente. Al contrario, comunas que concentran la población en uno o dos quintiles en desmedro de otros, aumentan la desviación estándar, alejándose de 0 . Mientras más bajo el índice, mayor es la mixtura social relativa en la comuna; números altos indican homogeneidad social (ya sea de altos o de bajos ingresos).

- Indice de pobreza comunal. Corresponde al porcentaje de habitantes de la comuna que se encuentran por debajo de la línea de pobreza por ingresos (nueva metodología), definida oficialmente de acuerdo con la Encuesta Casen 2013. Mientras más alta la cifra, mayor pobreza.

- Tasa de robos. Corresponde a la tasa de robos por 100.000 habitantes de tres diferentes tipos en 2013. Incluye casos policiales -denuncias y detenciones- de robo con violencia o intimidación, robo en lugar habitado y robo en lugar deshabitado ${ }^{10}$, registrados a nivel comunal. Cifras más altas indican más robos (Fundación Paz Ciudadana, s.f.).

- Dependencia administrativa. Pese a que la dependencia administrativa no es característica de la comuna sino de las escuelas, se incluyó una variable nominal de tres categorías para caracterizar la dependencia administrativa de las escuelas.

Estas variables independientes fueron luego sometidas a análisis de regresión logística multinomial con la variable dependiente "composición social del establecimiento", de tres categorías: escuelas segregadas desaventajadas, escuelas mixtas, escuelas segregadas aventajadas. El análisis de regresión logística predice la probabilidad de que un evento ocurra (las categorías de la variable dependiente) si se da una serie de condiciones (las variables independientes). Lo que se estima en la regresión logística para cada sujeto no es un valor de Y, sino el logaritmo de la probabilidad de que le ocurra un evento, frente a la probabilidad de que no le ocurra; al cociente entre

10 Se trata de tres tipos de robos que constituyen experiencias muy intimidantes e insegurizadoras para las víctimas y quienes los rodean. Lo que interesa inferir es la sensación de temor, de la cual no hay un indicador más directo. Temor a ser víctima de delincuencia común, particularmente el robo que, de acuerdo con el prejuicio social, es protagonizado por individuos de clase baja. 
ambos se le denomina odd. Se trata de identificar aquellas variables que implican cambios en esa ratio de probabilidad, aumentándolo o disminuyéndolo de forma significativa.

El análisis se llevó a cabo solo con los establecimientos urbanos de diez alumnos como mínimo en cuarto básico de la RMS ( $N=$ 1.605). Los establecimientos rurales y/o muy pequeños podrían sesgar los resultados pues, en muchos casos, tienen uno o dos alumnos en $4^{\circ}$ básico, es decir, el número es insuficiente para sostener una clasificación y análisis de su composición social ${ }^{11}$.

\section{Resultados}

\subsection{Composición social de las escuelas}

Los estudiantes de escuelas urbanas del país presentan la siguiente distribución: el 45,8\% estudia en escuelas de NSE bajo el promedio nacional; 33,6\% en escuelas sobre ese promedio; y 20,6\% en escuelas de NSE en torno al promedio nacional ${ }^{12}$. En la Región Metropolitana, la distribución es similar: 43,8\%; 33,9\%; y 22,3\%, respectivamente. Como punto de referencia, la proporción de escuelas mixtas en países como Suecia, Dinamarca y Canadá no baja del 60\%, usando este mismo método de clasificación y el mismo criterio de significación estadística respecto de la diferencia con el promedio nacional; en los países de la OECD es de $40 \%$ aproximadamente, en promedio (OECD, 2010).

En cuanto a la composición social interna en los tres tipos de escuelas urbanas, la Tabla 1 muestra la distribución de los alumnos según su quintil de NSE, a nivel nacional. Puede observarse segregación en dos grupos, en el sentido de que un grupo concentra la mayoría de los alumnos en los quintiles 1 y 2 y el otro lo hace en el quintil 5, seguido del 4. Por otra parte, el primer grupo apenas

11 De acuerdo al Simce 2013, la condición urbano o rural no se aplica a la comuna sino a la escuela. Muchas comunas de reconocida urbanidad tienen escuelas en entornos rurales dentro de sus límites.

12 Los estudiantes en escuelas rurales desaventajadas, aventajadas y en el promedio nacional de NSE, son $87,4 \% ; 0,9 \%$; y $11,7 \%$ respectivamente. Se omiten de este análisis. 
tiene estudiantes de los quintiles superiores, en tanto que el segundo grupo apenas tiene de los quintiles inferiores; las llamaremos escuelas "segregadas desaventajadas" y "segregadas aventajadas", respectivamente. En cambio, las escuelas de NSE cercano al promedio nacional presentan más diversidad o mixtura social, en la medida en que los estudiantes se concentran en los tres quintiles intermedios, sin despoblamiento de los quintiles extremos; los cinco quintiles están presentes en el 80\% de las escuelas de este grupo. La Tabla 6 en Anexos muestra ejemplos de escuelas mixtas con la distribución bruta de sus alumnos en los cinco quintiles de NSE. Más detalles descriptivos de las escuelas mixtas en Ortiz $(2015,2016)$.

Tabla 1

Composición social por quintiles de NSE (Q) de los alumnos en las escuelas urbanas de los tres tipos

\begin{tabular}{lccc}
\hline Quintiles de NSE & Desaventajadas & Mixtas & Aventajadas \\
Q1 & $29,5 \%$ & $9,4 \%$ & $1,5 \%$ \\
Q2 & $30,9 \%$ & $20,1 \%$ & $5,1 \%$ \\
Q3 & $22,2 \%$ & $27,0 \%$ & $10,5 \%$ \\
Q4 & $14,7 \%$ & $32,5 \%$ & $28,1 \%$ \\
Q5 & $2,6 \%$ & $11,0 \%$ & $54,8 \%$ \\
\hline Total & $100,0 \%$ & $100,0 \%$ & $100,0 \%$ \\
\hline
\end{tabular}

Fuente: Elaboración propia a partir de base de datos Simce $20134^{\circ}$ básico.

Nota: $N=177.437$.

\subsection{Composición social escolar y variables comunales}

Se analizaron 48 comunas de la región ${ }^{13}$ (se anexa tabla descriptiva). Un resultado preliminar, que anticipa e ilustra lo que más adelante comunica la regresión logística, es la identificación de las comunas con mayor concentración de escuelas inclusivas. Las Tablas 2 y 3 muestran las comunas con los mayores y menores porcentajes de estudiantes de escuelas socialmente inclusivas, respectivamente, junto con algunos datos socioeconómicos de esas comunas (en el Anexo el listado completo).

13 Se excluyeron del análisis cuatro comunas por poseer solo una escuela urbana: Alhué, María Pinto, San Pedro y Pirque. 
La Tabla 2 muestra que, salvo excepciones, las escuelas mixtas se ubican en comunas también socialmente mixtas, cuyos hogares se ubican en todos los quintiles de ingreso. Son comunas cuya composición social residencial es heterogénea, si se tiene en cuenta que presentan valores entre 0,06 y 0,12 en el índice respectivo que fluctúa entre 0,02 y 0,30. En La Cisterna y San Miguel las escuelas mixtas se acompañan de una proporción mayor de segregadas aventajadas, lo que podría explicarse por su composición social residencial heterogénea, con quintiles 4 y 5 bien poblados. San Joaquín, conocida como comuna de población modesta, incorporó población de quintiles superiores, lo que puede explicar su mixtura escolar. Esta comuna optó hace pocos años por cambiar el uso de una parte significativa de sus suelos, de industrial a residencial, en una franja que atraviesa tres estaciones de Metro, lo que derivó en un crecimiento de la inversión inmobiliaria orientada a grupos medios y medio-altos. Independencia es un caso atípico, porque tiene una gran proporción de matrícula aventajada, sin embargo, el ingreso promedio de los hogares es más bien bajo, lo que hace suponer que recibe escolares aventajados de otras comunas atraídos por colegios de prestigio para ellos. Otro hecho de la Tabla 2 es la presencia de comunas periurbanas no contiguas, como Curacaví. Puede verse aquí el efecto de la migración de sectores de ingresos altos de comunas centrales, en busca de condiciones de vida diferentes de las que ofrece la metrópoli (De Mattos et al., 2014), compartiendo el territorio con una población local de menor calificación ocupacional, en parte trabajadores rurales. 


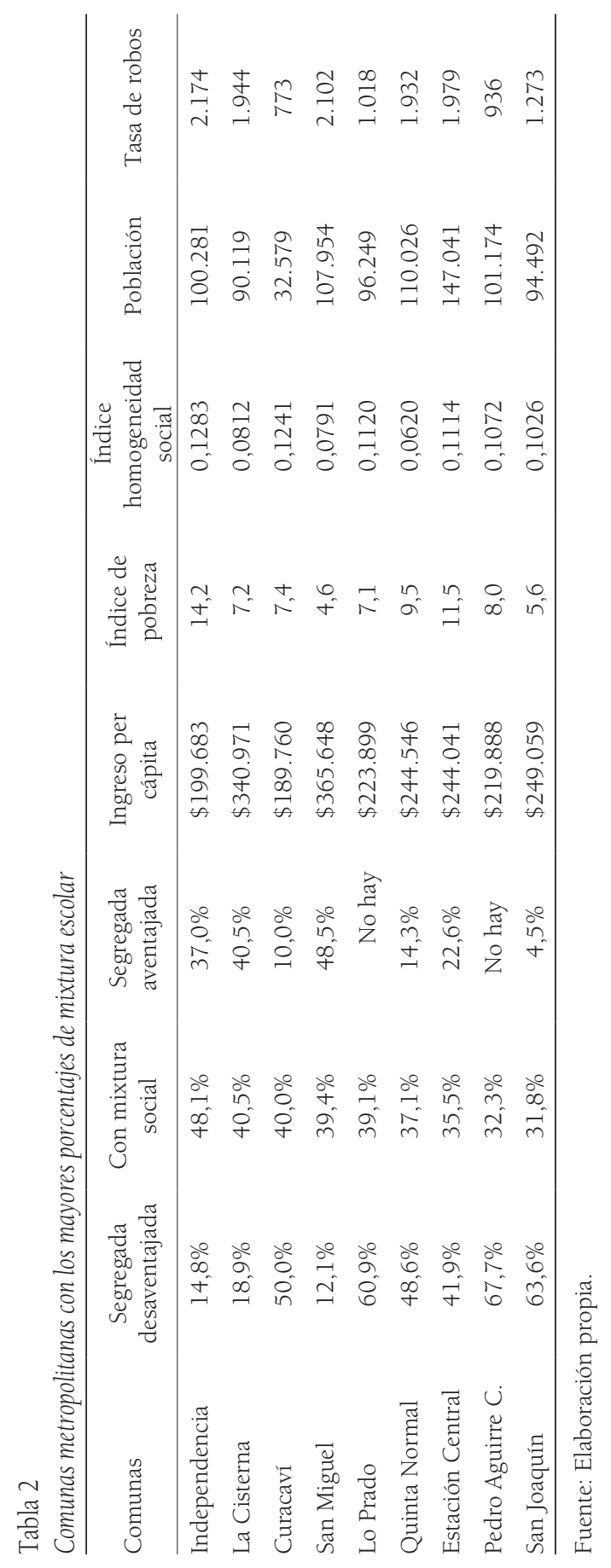




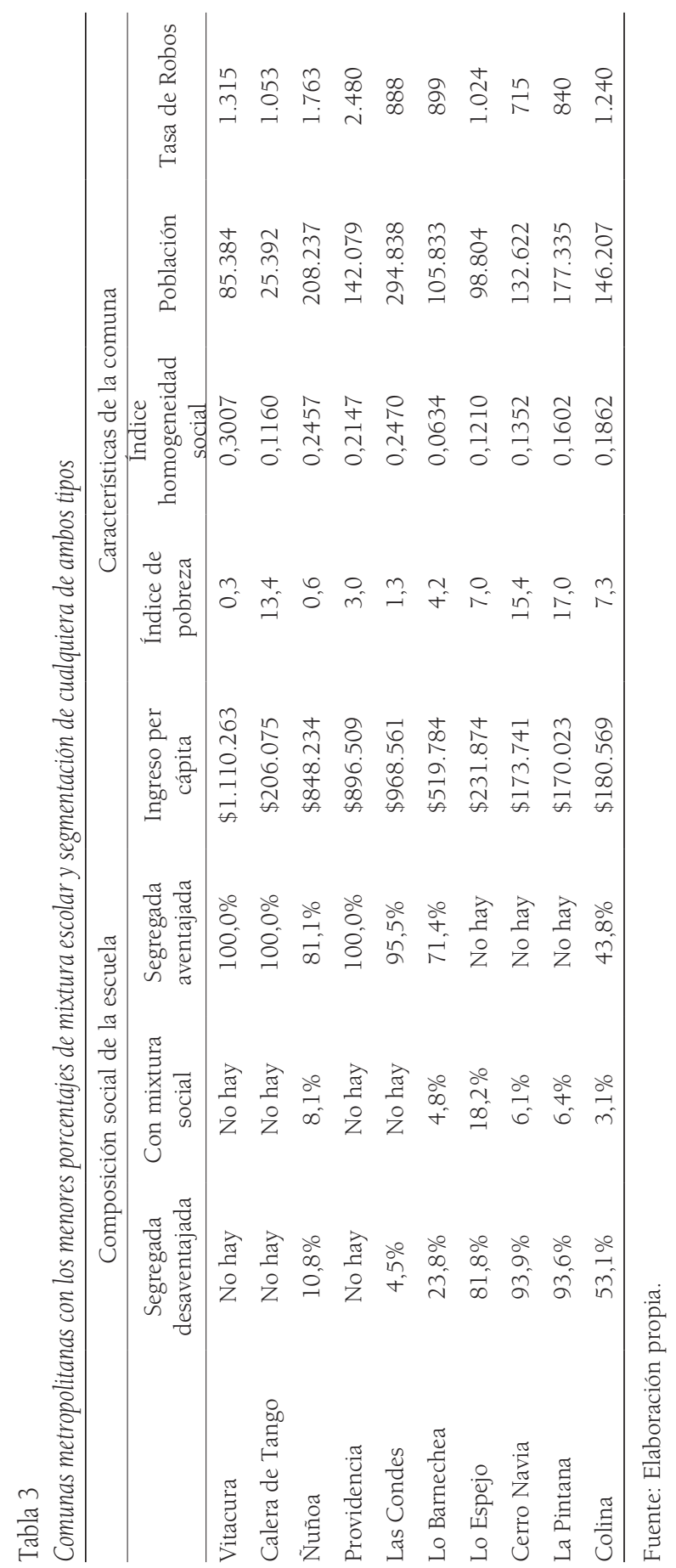


La Tabla 3, en contraposición, muestra comunas caracterizadas por la predominancia acentuada de escuelas segregadas, ya sean aventajadas o desaventajadas, o de los dos tipos juntos. Son comunas más homogéneas en su composición social residencial inclinadas a un extremo u otro de la distribución socioeconómica. Lo Barnechea es interesante, pues a partir de su alto grado de mixtura social comunal se hubiese pronosticado allí un porcentaje más elevado de escuelas mixtas. Pero su tamaño, el alto precio del suelo, el alto ingreso de sus élites, la hacen apta para el desarrollo de la oferta de colegios de alto precio y la segregación consecuente. La comuna se asentó en el pueblo rural del mismo nombre, grupo social que ha subsistido demográficamente, y se concentra hoy en sus propias escuelas.

El modelo con las variables independientes declaradas anteriormente - excepto "índice de pobreza" y "superficie de la comuna" que quedaron fuera ${ }^{14}$ - ajustó los datos mejor que un modelo nulo (Chi 2 significación estadística $=0,000$ ), con un pseudo R2 de Nagelkerke =0,566 y de McFadden =0,318. Es un modelo solo de efectos principales; pese a que en los ensayos previos se incluyeron numerosas interacciones entre las variables, ninguna mejoró el modelo. De acuerdo con el test de Pearson, el modelo no ajustó adecuadamente los datos (sig. = 0,004), pero el test Deviance indicó lo contrario $(\operatorname{sig} .=0,104)^{15}$. Los valores observados y los pronosticados por el modelo (Tabla 4) coinciden en el 65,2 de los casos, aunque este acierta más en predecir las escuelas segregadas de ambos tipos que las mixtas.

14 Producto de la exploración de los datos y los resultados, se agregó al modelo la variable independiente "prevalencia de matrícula particulares pagadas", es decir, el porcentaje de estudiantes de $4^{\circ}$ básico en escuelas particulares pagadas en la comuna. No prevista inicialmente, tiene un lugar en los resultados, como se verá más adelante. La variable se integró satisfactoriamente al modelo. Se siguió el método por pasos, con entrada hacia delante de las variables independientes.

15 Se espera un valor no significativo para rechazar la hipótesis nula de que los valores observados y los ajustados son muy diferentes. Cuando hay muchas covariables numéricas - como en este caso- se dice que estos test de la bondad de ajuste del modelo no son útiles, porque las subpoblaciones posibles son muchas, dejando celdas vacías a menos que en la opción Delta se especifique un número pequeño entre 0 y l para las celdas vacía, y así dar estabilidad al modelo. 
Tabla 4

Clasificación de las escuelas según el modelo

\begin{tabular}{lcccc}
\hline \multirow{2}{*}{ Observado } & \multicolumn{4}{c}{ Pronosticado } \\
\cline { 2 - 5 } & $\begin{array}{c}\text { Segregada } \\
\text { desaventajada }\end{array}$ & $\begin{array}{c}\text { Con mixtura } \\
\text { social }\end{array}$ & $\begin{array}{c}\text { Segregada } \\
\text { aventajada }\end{array}$ & $\begin{array}{c}\text { Porcentaje } \\
\text { correcto }\end{array}$ \\
\hline Segregada desaventajada & 582 & 40 & 81 & $82,8 \%$ \\
Con mixtura social & 183 & 77 & 98 & $21,5 \%$ \\
Segregada aventajada & 84 & 62 & 398 & $73,2 \%$ \\
\hline Porcentaje global & $52,4 \%$ & $11,0 \%$ & $35,6 \%$ & $65,2 \%$ \\
\hline
\end{tabular}

Fuente: Elaboración propia.

La Tabla 5 describe el efecto de cada variable independientemente del modelo ${ }^{16}$. De acuerdo con el parámetro Exp(B) ninguna de las variables afecta de manera dramática la probabilidad de una escuela de pertenecer a uno de los tres tipos de la variable dependiente, excepto la dependencia particular pagada a las escuelas segregadas aventajadas. En vez de interpretar los $\operatorname{Exp}(B)$ y calcular los odds, lo interesante aquí es el comportamiento diferencial de esas variables entre las escuelas mixtas y las segregadas aventajadas, con referencia a las segregadas desaventajadas. Así, en la Tabla 5 se lee que el tamaño poblacional de la comuna no distingue a las escuelas mixtas en referencia a las segregadas desaventajadas (sig. $=0,169$ ), pero sí distingue a las escuelas segregadas aventajadas (sig. $=0,000$ ) de ese mismo referente. En este caso, el signo positivo de B expresa que estas últimas están en comunas de tamaño poblacional mayor. Por otra parte, tanto las escuelas mixtas como las segregadas aventajadas pertenecen a comunas de ingreso per cápita mayor que las comunas donde están las segregadas desaventajadas. La Tabla 7 en el Anexo muestra además que las aventajadas están en las comunas del mayor ingreso per cápita promedio. De acuerdo con estas claves de lectura de los datos de la Tabla 5, otros resultados son los siguientes.

16 Se omitió el intercepto en el análisis, pues su interpretación carece de sentido en este caso. 
Tabla 5

Modelo de regresión logística multinomial. Estimaciones de los parámetros

\begin{tabular}{|c|c|c|c|c|c|c|}
\hline \multicolumn{2}{|c|}{ Tipo composición social escuela ${ }^{a}$} & \multirow{2}{*}{$\frac{\text { B }}{0,000001}$} & \multirow{2}{*}{$\begin{array}{l}\text { Error típ. } \\
0,0000005\end{array}$} & \multirow{2}{*}{$\begin{array}{r}\text { Wald } \\
1,896\end{array}$} & \multirow{2}{*}{$\begin{array}{r}\text { Sig. } \\
0,169\end{array}$} & \multirow{2}{*}{$\begin{array}{r}\operatorname{Exp}(B) \\
1,000\end{array}$} \\
\hline \multirow{8}{*}{$\begin{array}{l}\text { Con } \\
\text { mixtura } \\
\text { social }\end{array}$} & Población comuna & & & & & \\
\hline & Robos en la comuna & 0,001 & 0,00013 & 19,256 & 0,00001 & 1,001 \\
\hline & Ingreso per cápita & 0,000004 & 0,000001 & 23,604 & 0,00000 & 1,000 \\
\hline & Escuela municipal & $-3,134$ & 0,368 & 72,512 & 0,00000 & 0,044 \\
\hline & $\begin{array}{l}\text { Escuela p. } \\
\text { subvencionada }\end{array}$ & $-1,257$ & 0,321 & 15,379 & 0,00009 & 0,284 \\
\hline & Escuela p. pagada & $-0,278$ & 0,827 & 0,113 & 0,737 & 0,757 \\
\hline & $\begin{array}{l}\text { Prevalencia matrícula } \\
\text { p. pagada }\end{array}$ & $-0,025$ & 0,009 & 7,660 & 0,006 & 0,975 \\
\hline & $\begin{array}{l}\text { Índice homogeneidad } \\
\text { social comuna }\end{array}$ & $-5,581$ & 1,857 & 9,029 & 0,003 & 0,004 \\
\hline \multirow{8}{*}{$\begin{array}{l}\text { Segregada } \\
\text { aventajada }\end{array}$} & Población comuna & 0,000002 & 0,000001 & 23,830 & 0,0000 & 1,000 \\
\hline & Robos en la comuna & 0,0005 & 0,0001 & 14,868 & 0,0001 & 1,001 \\
\hline & Ingreso per cápita & 0,000008 & 0,000001 & 76,728 & 0,0000 & 1,000 \\
\hline & Escuela municipal & $-6,197$ & 0,506 & 150,110 & 0,0000 & 0,002 \\
\hline & $\begin{array}{l}\text { Escuela p. } \\
\text { subvencionada }\end{array}$ & $-2,615$ & 0,328 & 63,394 & 0,0000 & 0,073 \\
\hline & Escuela p. pagada & 1,444 & 0,673 & 4,607 & 0,032 & 4,238 \\
\hline & $\begin{array}{l}\text { Prevalencia matrícula } \\
\text { p. pagada }\end{array}$ & $-0,011$ & 0,008 & 1,587 & 0,208 & 0,990 \\
\hline & $\begin{array}{l}\text { Índice homogeneidad } \\
\text { social comuna }\end{array}$ & $-5,830$ & 1,961 & 8,833 & 0,003 & 0,003 \\
\hline
\end{tabular}

Nota: a: La categoría de referencia es: segregada desaventajada.

Fuente: Elaboración propia.

La dependencia administrativa es una característica de las escuelas; pero la agregación de escuelas o matrícula de determinada dependencia puede caracterizar a una comuna. Así, como rasgo de las escuelas, las dependencias municipal y particular subvencionada son más probables en el grupo de segregadas desaventajadas que en los otros dos grupos, a juzgar por el valor negativo de B. Por el contrario, la dependencia particular pagada es más probable en el grupo de las segregadas aventajadas. La Tabla 8 del Anexo describe el cruce entre la dependencia administrativa y la composición social, confirmando esta información: el grupo desaventajado —el más numeroso- tiene aproximadamente la mitad de sus escuelas en cada una de las dependencias municipal y particular subvencionada; 
todas las particulares pagadas (salvo una) se encuentran en el grupo de las segregadas aventajadas, pese a que en este grupo son más numerosas las particulares subvencionadas; las escuelas mixtas son preponderantemente particulares subvencionadas y, en segundo lugar, municipales. Ahora bien, en cuanto característica comunal, la prevalencia de matrícula particular pagada es más probable en las comunas de las desaventajadas — grupo de referencia- que en las mixtas, de acuerdo con el B negativo. De hecho, la media de matrícula particular pagada en las comunas con mayor concentración de escuelas mixtas es menor que en las comunas de desaventajadas (ver datos descriptivos de las variables en la Tabla 7 del Anexo; la diferencia es significativa con 99\% de confianza). En el grupo de las aventajadas, esta variable no tiene significación estadística. En otras palaras, en las comunas donde abundan las escuelas mixtas, hay escasa o nula presencia de particulares pagadas.

El índice de homogeneidad social presenta valores negativos de B, tanto en el grupo de las escuelas mixtas como en el de las segregadas aventajadas, indicando de esta manera que la homogeneidad social de la comuna es más probable en el grupo de referencia, es decir, en el grupo de las segregadas desaventajadas. En consecuencia, los otros dos grupos tienen más probabilidad de ubicarse en comunas más heterogéneas. La Tabla 7 muestra a las escuelas mixtas con el valor más bajo de este índice (diferencia estadísticamente significativa con ambos grupos con un 95\% de confianza), verificando su mayor mixtura social. Finalmente, con relación a la tasa de robos, esta es mayor en las comunas de mayor concentración de escuelas mixtas y de segregadas aventajadas respecto de las comunas de las desaventajadas. En la Tabla 7 se observa que la media más alta de robos corresponde a las comunas de las escuelas aventajadas.

Con el fin de verificar el ajuste del modelo y la lectura de los parámetros, se modificó la variable dependiente multinomial en dos binominales: escuelas mixtas versus cada una de las segregadas. En cada regresión logística binominal desarrollada, la bondad de ajuste de los datos resultó satisfactoria según el test de Hosmer y Lemeshow (sig. = 0,530 para el análisis de las escuelas mixtas con las aventajadas y sig. = 0,375 con las desaventajadas). En las tablas de clasificación, 
los valores pronosticados con acierto fueron globalmente $73,8 \%$ y $71,9 \%$ respectivamente; las escuelas mixtas pronosticadas con acierto fueron $67,9 \%$ y $42,2 \%$. La lectura de los parámetros fue en general la misma que en el modelo multinomial, con la diferencia de que el índice de homogeneidad social se mantuvo en el modelo mixtasdesaventajadas, pero no entró en el modelo mixtas-aventajadas.

\section{Discusión y conclusiones}

Un quinto de los estudiantes de $4^{\circ}$ básico del país en 2013 asistía a clases junto con compañeros de diversas condiciones socioeconómicas, en escuelas que podrían considerarse socialmente inclusivas. Dicha proporción es baja respecto del promedio de los países de la OCDE, pero podría aumentar en el futuro próximo por efecto de las medidas de la Ley de inclusión. Son escuelas identificables, cuya composición socioeconómica se caracteriza por la presencia en la misma aula de estudiantes de los cinco quintiles de NSE, en la gran mayoría de los casos, con predomino de los tres quintiles intermedios. Se puede discutir, no obstante, si la división en quintiles de NSE es o no la mejor forma de capturar la diferenciación social de la población; o si los componentes del NSE recogidos por el Simce reflejan bien la situación socioeconómica de las familias. La dependencia particular subvencionada es la que más aporta a la mixtura social, pues el 70\% de los estudiantes en escuelas mixtas es al mismo tiempo particular subvencionado; el 30\% restante es municipal.

A pesar de que el modelo predijo con más éxito a las escuelas segregadas de ambos tipos, entregó pistas valiosas para entender la mixtura escolar. En las comunas con más presencia relativa de escuelas inclusivas, el ingreso promedio comunal es superior al de las comunas segregadas desaventajadas, pero menor al de las comunas donde abundan las aventajadas. Son comunas que tienen mayor mixtura social residencial que las comunas donde prevalecen las segregadas de ambos tipos, es decir, coexisten grupos de los cinco quintiles de NSE. Son menos pobladas y tienen una tasa menor de robos que aquellas donde se asientan las segregadas aventajadas. Se caracterizan, además, por la ausencia o poca presencia de establecimientos particulares pagados. 
Una interpretación posible de la mixtura escolar en estas comunas sería la siguiente. Se configuraría en ellas una población heterogénea en términos socioeconómicos, probablemente entre los deciles dos y nueve, aunque con distribución variable según la comuna. Esta heterogeneidad socioeconómica interna genera algún nivel de segregación residencial en el modo emergente, conformando enclaves de familias de mejores ingresos, cercanos a barrios de familias de escasos recursos. Los "otros" de nivel social más bajo y relativamente vecinos serían menos temidos que en las comunas ricas. Existen aquí pocos colegios particulares pagados, o ninguno, porque el ingreso promedio de sus habitantes y/o el tamaño poblacional de la comuna no generan demanda suficiente para que se instale allí ese tipo de colegios. En consecuencia, la élite socioeconómica local no tiene otra opción que enviar a sus hijos a establecimientos particulares subvencionados. Dada su gran variedad estructural — pequeños, grandes, con y sin copago- estos establecimientos incorporan también a aquella parte de la población de menos recursos que busca escuelas con buena reputación.

Las comunas con mayor proporción de escuelas aventajadas también tienen cierta heterogeneidad social residencial, salvo excepciones como Vitacura. Como se discutió anteriormente, casi todas las comunas albergan residentes pertenecientes a los distintos grupos de la jerarquía ocupacional, en diferentes proporciones (Link at al., 2015). Pero debido a su numerosa población y a su ingreso promedio superior, existe oferta de colegios caros instalada allí y demanda con ingresos suficientes para segregarse en esos colegios, normalmente particulares pagados.

La mixtura escolar existente en ciertas comunas no sería ajena a procesos de gentrificación, al menos en parte. Junto a residentes de ingresos menores se han instalado allí capas medias y medias-altas atraídas por ciertas cualidades residenciales y sobre todo por una brecha de renta favorable ${ }^{17}$. De este modo, se configurarían espacios

17 El desplazamiento residencial entre comunas ocurre. Según la base de datos de la Encuesta Casen de 2013, en la RMS el 11,6\% de los encuestados del decil 7 de ingreso autónomo vivía hace cinco años en otra comuna; cifra que asciende al 12,5\% en el decil 8, a 23,7\% en el decil 9 y a $28,2 \%$ en el decil 10. 
residenciales de familias socioeconómicamente diversas que, por las razones interpretadas más arriba, convergen en la escuela particular subvencionada. Paradojalmente, estos grupos serían generadores de recomposición social, sin tener necesariamente motivaciones solidarias o de integración social. Es interesante pensar en ellos como eventuales agentes de cambio en favor de la inclusión, aunque su participación en la mixtura escolar es una hipótesis por verificar.

De acuerdo con estos resultados, una estrategia favorable a los propósitos de la Ley de inclusión sería apoyar y potenciar la mixtura ya existente, en las comunas donde es más frecuente, con políticas públicas escolares y no escolares (como vivienda y urbanización), pues tienen condiciones territoriales básicas que, tal vez, harían más probable sumar mixtura allí, que lograr una incipiente inclusión en las comunas segregadas. Las comunas de bajo y homogéneo ingreso de los hogares, presentan afinidad con la segregación escolar. Faltaría en ellas además un mecanismo de cambio. De acuerdo con las nuevas reglas de admisión, si hay más postulantes que cupos en una escuela determinada, se dará prioridad (segunda) al 15\% de estudiantes prioritarios, por curso, siempre que esas familias soliciten admisión en esa escuela. No es evidente que lo hagan sin la contribución de minorías activas, dado el patrón de elección de escuela al que son propensos, caracterizado por escasa información de los resultados académicos de las escuelas y preferencia por distancias cercanas entre la escuela y el hogar.

En ausencia de voluntad de las familias de elegir otra escuela, supuestamente mejor, la segregación escolar que existe hoy se mantendría constante, no revertiría. Por otra parte, es improbable que familias de escasos recursos migren a una comuna más aventajada en busca de una mejor alternativa escolar. Es más probable que familias de ingreso medio o medio-alto migren a comunas con "rent gap" en busca de viviendas accesibles y, en ese proceso, ocupen una escuela subvencionada del sector y gestionen su mejora, siempre y cuando no tengan la oportunidad de segregarse en escuelas particulares pagadas. No serán las familias de ingresos bajos, habitantes de comunas pobres, los sujetos del cambio — se sugiere aquí - sino las gentrificadoras en las comunas de ingreso medio con mixtura social. 
Se abren nuevas preguntas de investigación a partir de los resultados descritos. ¿Son efectivamente gentrificadoras las familias de NSE superiores que se observan en las escuelas mixtas? La acción rehabilitadora de los barrios que se atribuye a los gentrificadores, ¿de qué maneras se expresaría en las escuelas?, ¿qué podrían aportarles?, ¿varía el patrón de elección de escuela de las familias de bajos ingresos en las nuevas condiciones?, ¿es apropiado el modelo para predecir la composición social en otras regiones del país, o en ciudades y pueblos más pequeños? Este estudio muestra al sistema escolar como parte de un contexto socioeconómico y geográfico más amplio que moldea sus patrones de composición social. En este sentido, cabe preguntarse cuáles otras intervenciones, fuera del ámbito escolar, serían necesarias para recomponer la distribución social de las escuelas.

\section{Referencias}

Agostini, C. y Brown, Ph. (2007). Desigualdad geográfica en Chile. Revista de Análisis Económico, 22(1), 3-33.

Agostini, C., Hojman, D., Román, A., y Valenzuela, L. (2016). Segregación residencial de ingresos en el Gran Santiago, 1992-2002: una estimación robusta. Revista EURE, 42(127),159-184.

https://doi.org/10.4067/s0250-71612016000300007

Barton, M. (2016). An exploration of the importance of the strategy used to identify gentrification. Urban Studies, 53(1), 92-111. https://doi.org/10.1177/0042098014561723

Bellei, C. (2013). El estudio de la segregación socioeconómica y académica de la educación chilena. Estudios Pedagógicos, 39(1), 325-345. https://doi.org/10.4067/s0718-07052013000100019

Butler, T., Hamnett, C., \& Ramsden, M. (2013). Gentrification, education and exclusionary displacement in East London. International Journal of Urban and Regional Research, 37(2), 556-575.

https://doi.org/10.1111/1468-2427.12001

Casas-Cordero, C., Krause, A., y Herrera, R. (2011). Estimaciones de pobreza a nivel comunal, Chile 2009 (Informe de resultados). Santiago de Chile: Ministerio de Desarrollo Social.

Condliffe, B., Boyd, M., \& Deluca, S. (2015). Stuck in school: How social context shapes school choice for inner-city students. Teacher College Record, 117(3), 1-36. 
Córdoba, C. (2013). La elección de la escuela en sectores pobres. Resultados de un estudio cualitativo. Psicoperspectivas, 13(1), 56-67. https://doi.org/10.5027/psicoperspectivas-vol13-issuel-fulltext-301

De Mattos, C., Fuentes, L., y Link, F. (2014). Tendencias recientes del crecimiento metropolitano en Santiago de Chile. ¿Hacia una nueva geografía urbana? Revista INVI, 29(8), 193-219. https://doi. org/10.4067/s0718-83582014000200006

De Mattos, C., Riffo, L., Yáñez, G., y Salas, X. (2005). Reestructuración del mercado metropolitano de trabajo y cambios socio-territoriales en el Gran Santiago (Informe final proyecto Fondecyt 1040838). Santiago de Chile: Autor.

Donoso, S. y Arias, O. (2013). Desplazamiento cotidiano de estudiantes entre comunas de Chile: evidencia y recomendaciones de política para la nueva institucionalidad de la Educación Pública. Revista EURE, 39(116), 39-73.

http://dx.doi.org/10.4067/S0250-71612013000100002

Doucet, B. (2014). A process of change and a changing process: Introduction to the special issue on contemporary gentrification. Tijdschrift voor Economische en Sociale Geografie, 105(2), 125-139. https://doi.org/10.1111/tesg. 12075

Elacqua, G. (2012). The impact of school choice and public policy on segregation: Evidence from Chile. International Journal of Educational Development, 32(3), 444-453. https://doi.org/10.1016/j. ijedudev.2011.08.003

Fundación Paz Ciudadana (s.f.) Estadísticas policiales. Recuperado de http:// www.pazciudadana.cl/datoscomunales/

Frankenberg, E. (2013). The role of residential segregation in contemporary school segregation. Education and Urban Society, 45(5), 548-570. https://doi.org/10.1177/0013124513486288

Gallego, F. \& Hernando, A. (2008). On the determinants and implications of school choice: Semi-Structural simulations for Chile. Economía, 9(1), 197-244. https://doi.org/10.1353/eco.0.0016

Gorard, S. (2015). The uncertain future of comprehensive schooling in England. European Educational Research Journal, 14(3-4), 257-268. https://doi.org/10.1177/1474904115590214

Hamnett, C. (2003). Unequal city: London in the global arena. New York: Routledge. 
Hébrard, J. (2002). La mixité sociale à l'école et au collège. Rapport à Monsieur le Ministre de l'Éducation nationale. Paris: Ministère de L'éducation Nationale.

Hernández, M. y Raczynski, D. (2015). Elección de escuela en Chile: de las dinámicas de distinción y exclusión a la segregación socioeconómica del sistema escolar. Estudios Pedagógicos, 4(2), 127-141. https://doi.org/10.4067/s0718-07052015000200008

Hwang, J. (2016). While some things change, some things stay the same: Reflections on the study of gentrification. City and Community, 15(3), 226-230. https://doi.org/10.1111/cico.12188

Instituto Nacional de Estadísticas, INE. (2017a). Comunas: evolución de algunos indicadores demográficos 2002-2020. Recuperado de http://www.ine.cl/ estadisticas/demograficas-y-vitales

Instituto Nacional de Estadísticas, INE. (2017b). Presentación resultados definitivos Censo 2017. Recuperado de http://www.censo2017.cl/ wpcontent/uploads/2017/12/Presentacion_Resultados_Definitivos_ Censo2017.pdf.

Jordan, R. \& Gallagher, M. (2015). Does school choice affect gentrification? Metropolian Housing and Communities Policy Center brief, Urban Instititute. Recuperado de https://www.urban.org/sites/default/ files/publication/65841/2000374-Does-School-Choice-AffectGentrification.pdf

Landis, J. D. (2016). Tracking and explaining neighborhood socioeconomic change in U.S. Metropolitan areas between 1990 and 2010. Housing Policy Debate, 26(1), 2-52.

https://doi.org/10.1080/10511482.2014.993677

Link, F., Valenzuela, F., y Fuentes, L. (2015). Segregación, estructura y composición social del territorio metropolitano en Santiago de Chile. Complejidades metodológicas en el análisis de la diferenciación social en el espacio. Revista de Geografía Norte Grande, 62, 151-168. https://doi.org/10.4067/s0718-34022015000300009

López-Morales, E., Shin, H. B., \& Lees, L. (2016). Latin American gentrifications. Urban Geography, 37(8), 1091-1108.

https://doi.org/10.1080/02723638.2016.1200335

Martori, J. C. \& Apparicio, Ph. (2011). Changes in spatial patterns of the immigrant population of a Southern European Metropolis: The case of the Barcelona Metropolitan Area (2001-2008). Tijdschrift voor Economische en Sociale Geografie, 102(5), 562-581. https://doi.org/10.1111/j.1467-9663.2011.00658.x 
Martori, J. C., Hoberg, K., y Surinach, J. (2006). Población inmigrante y espacio urbano: Indicadores de segregación y pautas de localización. Revista EURE, 32(97), 49-62. https://doi.org/10.4067/s025071612006000300004

Ministerio de Educación de Chile, Mineduc (2012). Medidas de segregación escolar: discusión para el caso chileno. Serie Evidencias, 1(12). Recuperado de https://centroestudios.mineduc.cl/wp-content/uploads/ sites/100/2017/06/A1N12_Segregacion.pdf

Modrego, F., Ramírez, E., y Tartakowsky, A. (2009). La heterogeneidad espacial del desarrollo económico en Chile: Radiografía a los cambios en bienestar durante la década de los 90 por estimaciones en áreas pequeñas (Documento de trabajo No 9. Programa Dinámicas Territoriales Rurales). Santiago de Chile: Rimisp.

Monseur, C. et Crahay, M. (2008). Composition académique et sociale des établissements, efficacité et inégalités scolaires: une comparaison internationale. Revue Française de Pédagogie, 164, 55-65. https://doi.org/10.4000/rfp.2128

Organisation for Economic Co-operation and Development, OECD. (2009). PISA Data analysis manual, SPSS (2nd ed.). Paris: OECD Publishing.

Organisation for Economic Co-operation and Development, OECD. (2010). PISA 2009 Results: overcoming social background: Equity in learning opportunities and outcomes, Volume II. Paris: OECD Publishing.

Organisation for Economic Co-operation and Development, OECD. (2013). PISA 2012 Results: Excellence through equity: Giving every student the chance to succeed, Volume II. Paris: OECD Publishing.

Ortiz, I. (2015). Escuelas inclusivas en el contexto de segregación social del sistema escolar chileno. Revista Calidad en la Educación, 42, 93-122. https://doi.org/10.4067/s0718-45652015000100004

Ortiz, I. (2016). Actitudes de los estudiantes en escuelas segregadas y en escuelas inclusivas, hacia la tolerancia social y la convivencia entre pares. Revista Calidad en la Educación, 44, 68-97. https://doi. org/10.4067/s0718-45652016000100004

Rasse, A. (2015). Juntos, pero no revueltos. Procesos de integración social en fronteras residenciales entre hogares de distinto nivel socioeconómico. Revista EURE, 41(122), 125-143. https://doi.org/10.4067/s0250-71612015000100006

Ruiz-Tagle, J. (2016). La persistencia de la segregación y la desigualdad en barrios socialmente diversos: un estudio de caso en La Florida, Santiago. Revista EURE, 42(125), 81-108.

https://doi.org/10.4067/s0250-71612016000100004 
Ruiz-Tagle, J. y López, E. (2014). El estudio de la segregación residencial en Santiago de Chile: revisión crítica de algunos problemas metodológicos y conceptuales. Revista EURE, 40(119), 25-48. https://doi.org/10.4067/s0250-71612014000100002

Sabatini, F. y Brain, I. (2008). La segregación, los guetos y la integración social urbana: mitos y claves. Revista EURE, 34(103), 5-26. https://doi.org/10.4067/s0250-71612008000300001

Sabatini, F., Cáceres, G., y Cerda, J. (2001). Segregación residencial en las principales ciudades chilenas: tendencias de las tres últimas décadas y posibles cursos de acción. Revista EURE, 27(82), 21-42. https://doi.org/10.4067/s0250-71612001008200002

Sabatini, F., Rasse, A., Mora, P. y Brain, I. (2012). ¿Es posible la integración residencial en las ciudades chilenas? Disposición de los grupos medios y altos a la integración con grupos de extracción popular. Revista EURE 38(115), 159-194.

http://dx.doi.org/10.4067/S0250-71612012000300008

Sharkey, P. \& Faber, J. W. (2014). Where, when, why, and for whom do residential contexts matter? Moving away from the dichotomous understanding of neighborhood effects. Annual Review of Sociology, 40(1), 559-579. https://doi.org/10.1146/annurev-soc-071913-043350

Siegel-Hawley, G. (2013). City lines, county lines, color lines: The relationship between school and housing segregation in four southern metro areas. Teachers College Record, 115(6), 1-45.

Stillerman, J. (2016). Educar a niñas y niños de clase media en Santiago: capital cultural y segregación socioterritorial en la formación de mercados locales de educación. Revista EURE, 42(126), 169-186. https://doi.org/10.4067/s0250-71612016000200008

Thieme, C. y Rojas, X. (2009). Aspectos conceptuales y evidencia empirica para el diseño de un sistema benchmarking de apoyo a la selección de establecimientos educativos para sectores urbanos de Chile. (Informe final. Segundo concurso Fonide). Santiago de Chile: Ministerio de Educación.

Valenzuela, J. P., Bellei, C., y de los Ríos, D. (2009). Evolución de la segregación socioeconómica de los estudiantes chilenos y su relación con el financiamiento compartido. En Fondo de Investigación y Desarrollo en Educación (Ed.), Evidencias para politicas públicas en educación (pp. 231-284). Santiago de Chile: Ministerio de Educación.

Valenzuela, J. P., Bellei, C., y de los Ríos, D. (2014). Socioeconomic school segregation in a market-oriented educational system. 
The case of Chile. Journal of Education Policy, 29(2), 217-241. https://doi.org/10.1080/02680939.2013.806995

Recibido: 25/11/2017

Aceptado: 26/04/2018 
198 RELACIÓN ENTRE LA COMPOSICIÓN SOCIAL DE LA COMUNA Y LA DE LAS ESCUELAS EN LA REGIÓN METROPOLITANA DE SANTIAGO - I. Ortiz

\section{Anexo}

Tabla 6

Ejemplos de la composición social interna de las escuelas con mixtura social. Frecuencias brutas

\begin{tabular}{ccccccc}
\hline rbd & $\mathrm{q} 1$ & $\mathrm{q} 2$ & $\mathrm{q} 3$ & $\mathrm{q} 4$ & $\mathrm{q} 5$ & $\mathrm{~N}^{\circ}$ alumnos \\
\hline 3663 & 4 & 15 & 15 & 25 & 12 & 71 \\
3671 & 1 & 7 & 5 & 4 & 0 & 17 \\
3796 & 2 & 11 & 18 & 24 & 3 & 58 \\
3797 & 9 & 9 & 20 & 21 & 7 & 66 \\
3960 & 7 & 8 & 14 & 11 & 2 & 42 \\
4175 & 5 & 12 & 14 & 14 & 3 & 48 \\
9283 & 17 & 26 & 34 & 38 & 15 & 130 \\
9284 & 8 & 11 & 12 & 14 & 6 & 51 \\
9299 & 5 & 14 & 12 & 20 & 4 & 55 \\
9302 & 2 & 8 & 3 & 6 & 1 & 20 \\
\hline
\end{tabular}

Nota: *Rbd es el identificador de la escuela.

Fuente: Elaboración propia a partir de base de datos Simce 2013 para $4^{\circ}$ básico. 


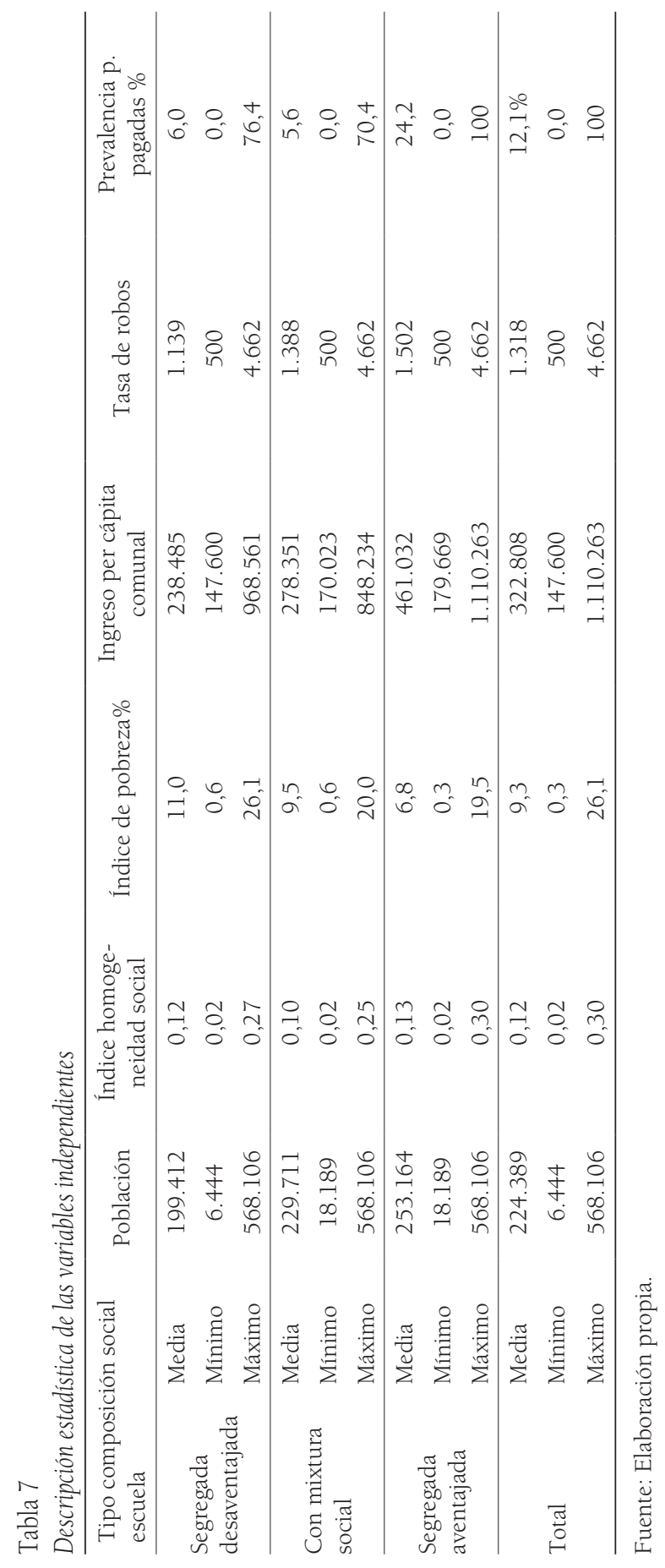


200 RELACIÓN ENTRE LA COMPOSICIÓN SOCIAL DE LA COMUNA Y LA DE LAS ESCUELAS EN LA REGIÓN METROPOLITANA DE SANTIAGO - I. Ortiz

Tabla 8

Cruce entre la dependencia administrativa y el tipo composición social de la escuela. Frecuencias brutas

\begin{tabular}{lcccc}
\hline \multicolumn{4}{c}{ Tipo composición social escuela } & Total \\
\hline Dependencia & Desaventajada & Mixta & Aventajada & \\
Municipal & 364 & 60 & 22 & 446 \\
P. subvencionda & 339 & 297 & 329 & 965 \\
P. pagada & 0 & 1 & 193 & 194 \\
Total & 703 & 358 & 544 & 1.605 \\
\hline
\end{tabular}

Fuente: Elaboración propia. 


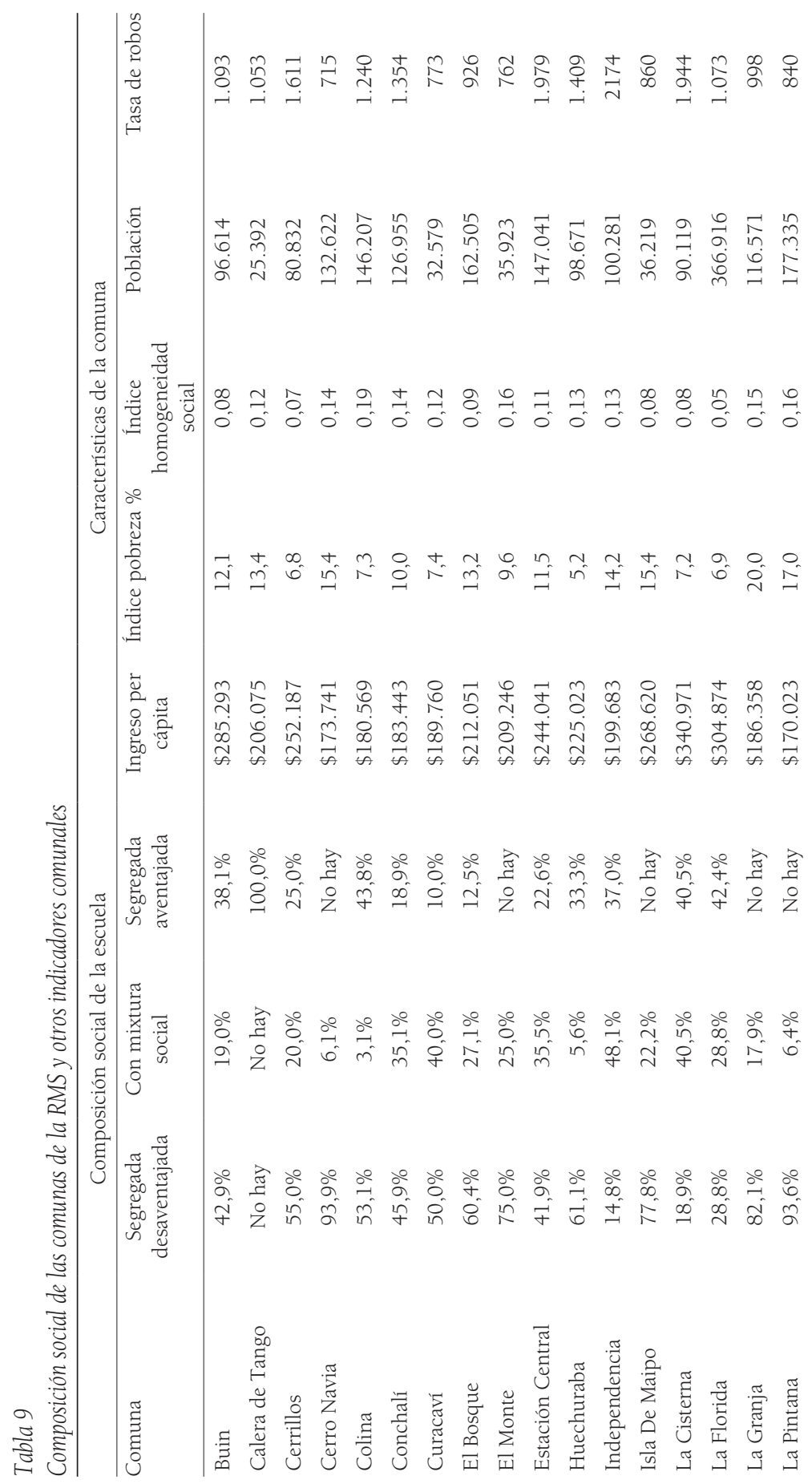




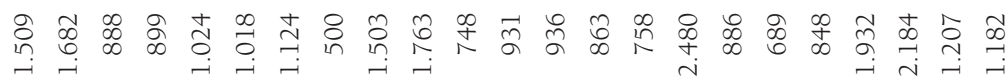

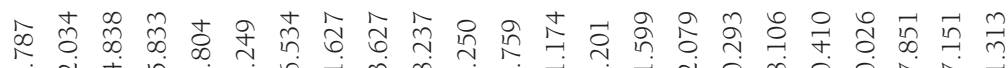

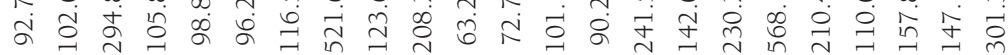

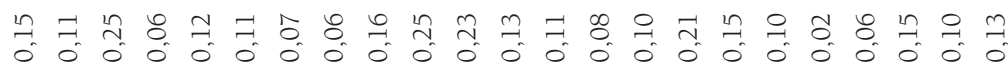

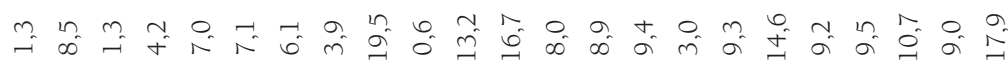

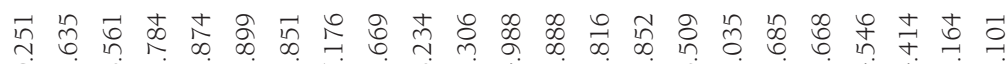

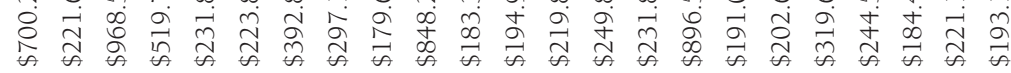

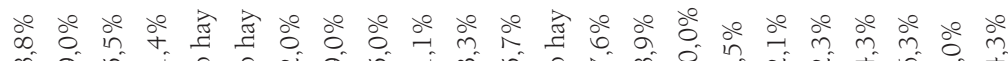

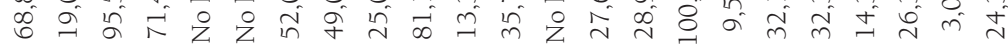

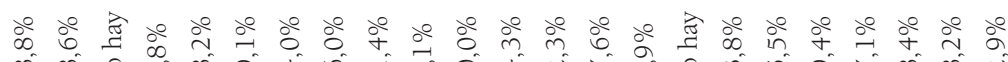

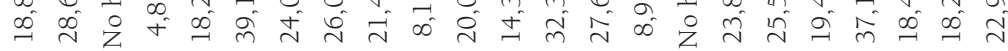

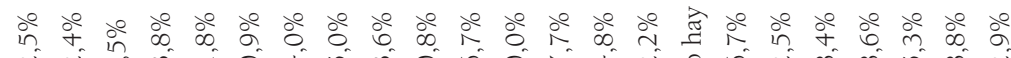

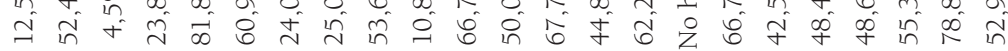

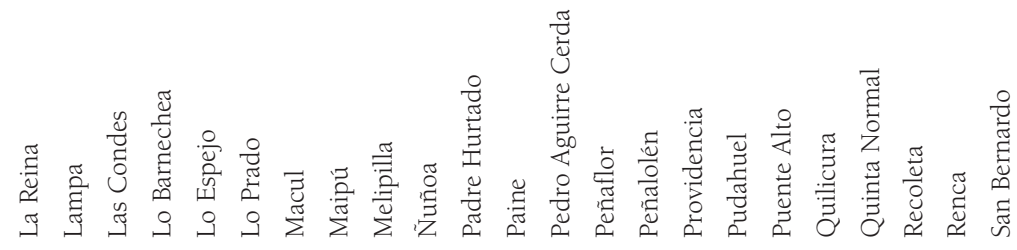




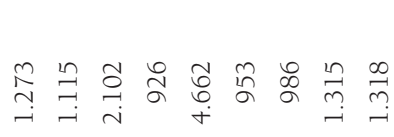

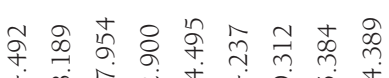

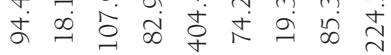

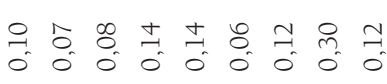

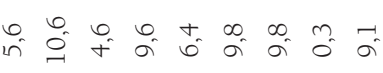

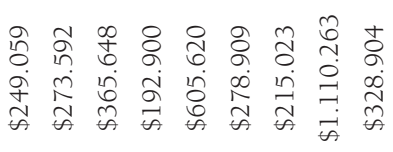

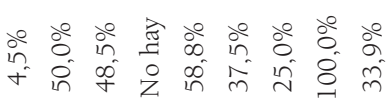

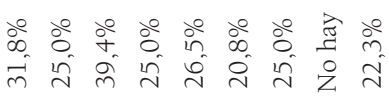

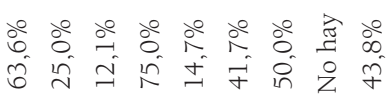

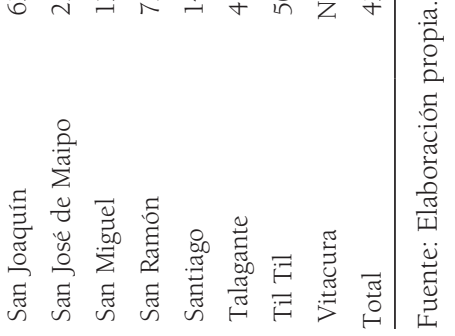

